\title{
The Price Index Effect and Macroeconomic Inefficiency*
}

\author{
Corrado Benassi \\ Università di Bologna \\ Alessandra Chirco \\ Università di Lecce \\ Caterina Colombo \\ Università di Bari and Università di Ferrara
}

\section{Introduction}

The macroeconomic literature on general equilibrium with monopolistic competition has heavily relied on the Dixit-Stiglitz (1977) model. The solution procedure of the latter is known to involve an approximation, in that each firm is assumed not to perceive the effect of its own price decisions on the aggregate price index. The implications of this "negligibility hypothesis" lave recently been discussed in a number of papers (Yang and Heijdra, 1993; Dixit and Stiglitz,1993; D'Aspremont, Dos Santos Ferreira and Gérard-Varet, 1996), the focus of which is on identifying closed solutions of the model, and determining the equilibrium number of firms. The ain of this paper is to investigate the role of the price-index effect in a general equilibrium macroeconomic perspective, with particular emphasis on the inefficiency of aggregate outcomes. ${ }^{1}$

It is by now a well established result, that general equilibrium interactions magnify the partial equilibrium inefficiency of imperfect competition, through aggregate demand externalities (e.g., Blanchard and Kiyotaki, 1987) : since any single firm shares with all other firms the benefits (in terms of higher aggregate demand) of a reduction of its own price, non-cooperative equilibria arise, which are Pareto-dominated by cooperative outcomes with higher levels of production and demand. However, when this result is obtained within the framework of Dixit-Stiglitz monopolistic competition, an

* C. Benassi acknowledges financial support from the University of Bologna

1 The relevance of the price index effect in defining the optimal targets for monetary policy has been studied by Bratsiotis and Martin (1999), while the role of the price index effect in the analysis of income taxation has been emphasized by Wu and Zhang (2000). 
additional inefficiency is added to the inefficiency of the Nash solution, due to firms neglecting the price index effect: not only each agent chooses his price by taking as given the other agents' prices, but he does not consider the effect of his own price on the aggregate price - though the latter enters the relevant behavioural relations, through both the relative price, and the real aggregate demand levels.

When the cooperation problem is studied in models where the price index approximation is adopted, one of the consequences is that the size of the macroeconomic inefficiency, and hence the potential incentive to cooperate, turns out to be in fact independent of the number of agents - a result which is somewhat disappointing. In this paper, we show that the explicit consideration of the price index effect in the agents' decisions allows to specify a correct measure of the inefficiency due to non-cooperative behaviour, a measure which turns out to be positively correlated to the number of agents. ${ }^{2}$ This is consistent with the intuition that in the presence of aggregate demand externalities, any agent's awareness of the aggregate implications of his own decisions is stronger, the smaller is the number of agents. ${ }^{3}$ In a general equilibrium perspective, a sort of reversal of the Cournotion convergence theorem must hold.

Moreover, the Dixit-Stiglitz approach to monopolistic competition has been the theoretical set-up for addressing some basic issues in macroeconomic (New Keynesian) analysis, such as nominal rigidity and the real effects of monetary policy. One implication of our model is that also the degree of nominal rigidity and the welfare effects of nominal shocks depend on the number of agents. In the paper we show that the inclusion of the price index effect reduces the scope for nominal rigidity, and decreases the welfare effect of monetary shocks.

The paper is organized as follows. In section 2 we sum up a simple monopolistic competition macroeconomic model, and compare its standard Dixit-Stiglitz solution to the non-approximate solution. Section 3 addresses the issue of nominal rigidity and its aggregate implications. Some conclusions are gathered in section 4 .

\section{The consumer-producer model : alternative solutions}

Our reference model is the well known consumer-producer model with monopolistic competition, introduced by Ball and Romer $(1989,1990)$ and

2 An alternative channel through which the number of producers (product varieties) influences the macroeconomic equilibrium is a direct "preference for diversity" effect on utility, studied in Heijdra and van der Ploeg (1996) and Heijdra (1998).

3 We recall that the idea that a stronger decision-makers' awareness of their own influence on aggregate variables generates more efficient aggregate outcomes, also inspires, e.g., the debate on centralized vs decentralized union bargaining (Layard, Nickell and Jackman, 1991, ch.2). 
Blanchard and Fischer (1989, ch.8). The economy is populated by $N$ agents, each of whom is the only producer, by means of his own labour, of a differentiated commodity which enters symmetrically the consumption bundle of all agents. We recall the basic elements of this model. The utility function of any agent $i$ is :

$$
U_{i}=C_{i}-\frac{1}{\alpha} L_{i}^{\alpha}, \quad \alpha>1
$$

where $L_{i}$ is labour supplied and $C_{i}$ is the consumption bundle, defined by a CES sub-utility function :

$$
C_{i}=N\left[\frac{1}{N} \sum_{j=1}^{N} C_{i j}^{\frac{\sigma-1}{\sigma}}\right]^{\frac{\pi}{\sigma-1}}, \quad \sigma>1
$$

where $C_{i j}$ is the amount of good $j$ consumed by agent $i$. The production function is assumed to be linear in labour :

$$
Y_{i}=L_{i}
$$

As a consumer, each agent $i$ maximizes his utility with respect to all $C_{i j}$ 's. We aggregate individual demand functions over all agents, and assume that the transaction technology imposes that (per capita) nominal money spending equals the (per capita) nominal money stock, $M=P C$, where $C=(1 / N) \sum C_{i}$ is average consumption. Then the following market demand for each good $j$ is obtained:

$$
Y_{j}^{d}=\left(\frac{P_{j}}{P}\right)^{-\sigma} \frac{M}{P}
$$

where $P$ is the dual price index :

$$
P=\left[\frac{1}{N} \sum_{j=1}^{N} P_{j}^{1-\sigma}\right]^{\frac{1}{1-\sigma}}
$$

By substituting (2) into (1) and making use of the budget constraint, $C_{i}=$ $\left(P_{i} / P\right) Y_{i}$, we get the following indirect utility function

$$
V_{i}=\frac{P_{i}}{P} Y_{i}-\frac{1}{\alpha} Y_{i}^{\alpha}
$$

This is the objective function which agent $i$, as a producer, maximizes with the respect to the nominal price $P_{i}$ subject to the demand constraint given by (3) . 


\subsection{The approximate solution}

The standard solution to this model neglects the so called "price index effect", that is, $P_{i}$ is chosen under the assumption that $P$ be given, i.e. unaffected by $P_{i}$. Under symmetry, this approximation entails the following equilibrium values of the aggregate price level $P$ and the level of output $Y_{i}=Y$, produced by each agent $i$ :

$$
\begin{aligned}
& P=\left(\frac{\sigma}{\sigma-1}\right)^{\frac{1}{\sigma-1}} M \\
& Y=\left(\frac{\sigma-1}{\sigma}\right)^{\frac{1}{\sigma-1}}
\end{aligned}
$$

Of course, the efficient price-equal-marginal cost rule would entail a higher output and a lower $P$ :

$$
P=M \quad Y=1
$$

\subsection{The exact solution}

Let us consider an alternative solution to the producer's maximization problem, which is obtained once the effect of $P_{i}$ on the aggregate (average) price $P$ is taken into account. Maximization of (4) entails the following first order condition :

$$
\frac{P_{i}}{P}\left[1-\frac{\left(1-\varepsilon_{p}\right)}{\varepsilon_{d}}\right]=Y_{i}^{\alpha-1}
$$

where $\varepsilon_{p}=\left(\partial P / \partial P_{i}\right) /\left(P_{i} / P\right)$ is the elasticity of the aggregate price index with respect to $P_{i}$ and $\varepsilon_{d} \equiv\left(\partial Y_{i}^{d} / \partial P_{i}\right) /\left(P_{i} / Y_{i}^{d}\right)=\left[\sigma\left(1-\varepsilon_{p}\right)+\varepsilon_{p}\right]$, from (3). Consider now the ratio $\left(1-\varepsilon_{p}\right) / \varepsilon_{d}$. The denominator is demand elasticity; notice that $\varepsilon_{d}$ takes here into account the effects of $P_{i}$ on the relative price, both directly $(\sigma)$ and through the price index $\left(\sigma \varepsilon_{p}\right)$, as well as on the real money balances $\left(\varepsilon_{p}\right){ }^{4}$ The numerator captures the effect of an increase in $P_{i}$ on the price of the consumption bundle, which represents for agent $i$ as a consumer the reward for the labour he supplies. In this sense, the consumer-producer model accounts neatly for all general equilibrium implications of any agent's individual decisions. The ratio $\left(1-\varepsilon_{p}\right) / \varepsilon_{d}$ is therefore a measure of the desired price margin over marginal cost, which takes into account the effect of any change in the agent's price not only on his demand, but also on his purchasing power in terms of the overall consumption bundle. Evaluating these elasticities in the symmetric equilibrium, $\varepsilon_{p}=\varepsilon_{p}^{*}=1 / N$ and $\varepsilon_{d}=\varepsilon_{d}^{*}=\sigma[1-(1 / N)]+(1 / N)$, we obtain the

4 Notice that this solution is consistent with the procedure suggested by Yang and Heijdra (1993), which in our case coincides with that proposed by D'Aspremont et al. (1996). 
equilibrium values of $P$ and $Y$ :

$$
\begin{aligned}
& P=\left(\frac{\sigma\left(1-\frac{1}{N}\right)+\frac{1}{N}}{(\sigma-1)\left(1-\frac{1}{N}\right)+\frac{1}{N}}\right)^{\frac{1}{\sigma-1}} M \\
& Y=\left(\frac{(\sigma-1)\left(1-\frac{1}{N}\right)+\frac{1}{N}}{\sigma\left(1-\frac{1}{N}\right)+\frac{1}{N}}\right)^{\frac{1}{\sigma-1}}
\end{aligned}
$$

For any finite value of $N$, including the price index effect implies a higher equilibrium level of $Y$ and a lower $P$, with respect to the model's standard solution. More precisely, it is easy to check that we recover the efficient solution for $N$ approaching 1 , and the standard solution as $N$ approaches infinity. Although these convergence properties are clearly not unexpected, they carry with them some noteworthy implications.

Following a standard practice, we can characterize the macroeconomic inefficiency associated with monopolistic competition in terms of the output gap between the equilibrium and the efficient solutions. In the (standard) approximate solution, this gap is actually independent of $N$. This is somehow unsatisfactory, as one would expect that an inefficiency driven by demand-externality should depend on the agents' ability to perceive the general equilibrium implications of their choices - something which is in principle related to the number of agents. However, the approximate solution fails to convey this important point, since there the inefficiency results from the combined effect of (a) the non-cooperative behaviour implied by the decentralized decision making, and (b) the myopic: behaviour implicit. in disregarding the price index effect. Once the latter is amended for, the inefficiency due purely to lack of cooperation is fully brouglit out as positively related to the number of agents.

\section{The price index effect and nominal rigidity}

As is well known, the aggregate inefficiency generated by optimal individual choices is the key property, which made the model sketched above a most appropriate framework for the study of nominal rigidities. Since both the individual pricing rule and the degree of aggregate inefficiency are affected by the price index effect, the private incentive towards inertial behaviour and its macroeconomic consequences should be re-assessed in the light of this effect - as also should the possibility that both rigidity and flexibility be self-sustaining non-cooperative equilibria. 


\subsection{Private loss, welfare and nominal rigidity}

Small monetary shocks entail no private loss from nominal inertia, while the aggregate equilibrium being sub-optimal implies that this inertia has first order effects on aggregate variables. By applying the definition of social gain (loss) from non adjustment (as a proportion of the initial output), $d V / Y=$ $(\partial V / \partial M) d M / Y$ evaluated at the symmetric equilibrium, we obtain for the non approximate solution :

$$
\frac{d V}{Y}=\frac{\left(1-\frac{1}{N}\right)}{\sigma\left(1-\frac{1}{N}\right)+\frac{1}{N}} \frac{d M}{M}=\frac{1-\varepsilon_{p}^{*}}{\varepsilon_{d}^{*}} \frac{d M}{M}
$$

the coefficient of which is lower than $1 / \sigma$ and collapses to it as $N$ tends to infinity. As expected, the measure of the welfare gain (loss) of nominal inertia is given by the degree of monopoly power, which in our case has already been shown to be lower than in the approximate case. In the presence of nominal rigidity, our flexible solution being closer to the efficient one makes aggregate welfare less sensitive to nominal disturbances.

Large shocks require an explicit evaluation of the private loss $\mathcal{L}$ from non adjustment, to be compared with the menu cost. ${ }^{5}$ Recall that, when measured in terms of the initial output, $\mathcal{L}$ evaluated by a second order Taylor expansion is $-\left[\left(\partial^{2} V / \partial M \partial P_{i}\right)^{2} / 2\left(\partial^{2} V / \partial P_{i}^{2}\right)\right](d M)^{2} / Y$. This in our case becomes :

$$
\mathcal{L} \approx \frac{-\frac{1}{2}(\alpha-1)^{2}\left(\varepsilon_{d}^{*}+\varepsilon_{p}^{*}-1\right)^{2}}{\left(\left(\left(1-\frac{1}{N}\right)\left(\sigma(\sigma-1)-\frac{1}{N}(2 \sigma-1)(\sigma-2)\right)\right)-\frac{\varepsilon_{d}^{*}+\varepsilon_{i}^{*}-1}{\varepsilon_{d}^{*}} H\right)}\left(\frac{d M}{M}\right)^{2}
$$

where

$$
\begin{aligned}
H= & H(\alpha, \sigma, N)=\sigma(1+\sigma \alpha)-\frac{\sigma}{N}(2 \alpha(\sigma-1)+\sigma+1)+ \\
& +\frac{1}{N^{2}}((\sigma-1)(\sigma(\alpha+1)-\alpha+1))
\end{aligned}
$$

Notice that the coefficient of $\frac{1}{2}(d M / M)^{2}$ in $\mathcal{L}$ tends to its standard (approximate solution) value $\left[(\sigma-1)(\alpha-1)^{2} /(\alpha \sigma-\sigma+1)\right]$ as $N$ tends to infinity. To compare $\mathcal{L}$ with the latter for different values of $N$, we assign to $\alpha$ and $\sigma$ the benchmark values suggested by Dixon and Hansen (1999), $\alpha=6$ and $\sigma=4$, in which case the approximate value of the coefficient is 3.571 4. The convergence to this value is plotted in Figure 1.

The intuition for the private loss to be systematically higher under the exact solution is the following. By non-adjusting prices agents give up

5 The procedure for the evaluation of the private loss from inertial behaviour and its aggregate consequences is fully worked out in Benassi, Chirco and Colombo $(1994$, ch.7). 


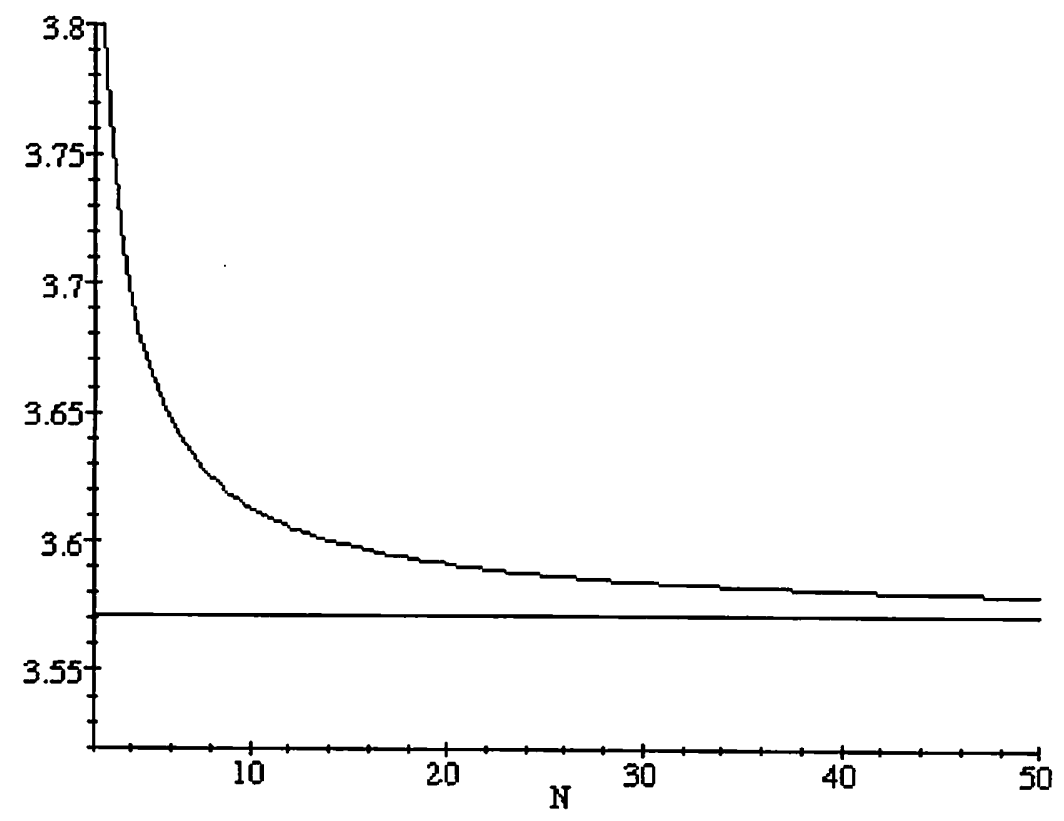

\section{Figure 1}

not only the opportunity of changing their desired relative price directly, but also the possibility of counteracting (via their own price change) the aggregate shock they perceive in real money balances, given the inertial behaviour of all other agents. Therefore, a full awareness of the aggregate implications of individual decisions narrows the scope for rigidity to be an equilibrium solution of the model : the size of the menu cost required to induce inertia is higher, the lower is the number of price-making agents.

The social gain (loss) from large monetary shocks under price rigidity, evaluated by a second order Taylor expansion at the symmetric flexible equilibrium, is

$$
\frac{d V}{Y} \approx \frac{\left(1-\varepsilon_{p}^{*}\right)}{\varepsilon_{d}^{*}} \frac{d M}{M}-\frac{1}{2} \frac{(\alpha-1)\left(\varepsilon_{d}^{*}+\varepsilon_{p}^{*}-1\right)}{\varepsilon_{d}^{*}}\left(\frac{d M}{M}\right)^{2}
$$

The coefficient of first order term coincide with (6); therefore it is lower than in the standard case, and is increasing in $N$; the coefficient of the second order term is higher than its approximate counterpart, and is decreasing in $N$. By applying to (7) the same parameter values considered above, the overall effect of a positive shock on $M$ is a social gain, which is in fact increasing in $N$ and converges to its approximate value from below. 


\subsection{Multiplicity of equilibria}

As Ball and Romer (1991) point out, the presence of menu cost may be consistent with both price rigidity and price flexibility being Nash equilibria. For this multiplicity result to emerge, the size of the menu cost must be greater than the private loss from non adjustment when all other agents do not adjust, and smaller than the private loss from non adjustment when all other agent do adjust their prices. In section 3.1 we have shown that for reasonable parameter values, the private loss from non adjustment in the first case is higher here than in the standard case. As for the private loss from rigidity when the other agents adjust, this is now :

$$
\mathcal{L}^{\prime} \approx-\frac{1}{2}\left(\left(\left(1-\frac{1}{N}\right)\left(\sigma(\sigma-1)-\frac{1}{N}(2 \sigma-1)(\sigma-2)\right)\right)-\frac{\varepsilon_{d}^{*}+\varepsilon_{p}^{*}-1}{\varepsilon_{d}^{*}} H\right)\left(\frac{d M}{M}\right)^{2}
$$

For the same parameter values, this expression is lower than its approximate equivalent, to which it converges from below as $N$ tencls to infinity. Again, it is not difficult to capture the economic intuition of this behaviour. Any agent is now aware of his role in defining the aggregate price; therefore he perceives that adjustment from all other agents does not imply full adjustment of the aggregate price and real money balances. This makes for him less costly to refrain from changing his own price, when all other agents do change theirs.

As a consequence, the range of menu cost values which support multiplicity of equilibria (sticky and flexible prices) shrinks - a result which, in the spirit of Ball and Romer, can be interpreted as a reduction of the scope for coordination failures.

\section{Concluding remarks}

The idea that imperfect competition makes for lower activity levels has of course been known for a long time; the New Keynesian literature highlighted that general equilibrium interactions magnify this inefficiency, and offered an interpretation of the latter in terms of endogenous insufficient aggregate demand. Within this framework, this paper deals with the following question : is the efficiency gap driven by imperfect competition larger, when few agents are endowed with market power, or rather is it larger when market power is widely spread across traders? More generally, how does the number of decision makers affect the incentive to internalize macroeconomic externalities?

The standard reference model on aggregate demand externality - the Dixit-Stiglitz model of monopolistic competition - yields the disappointing result that the number of interacting agents is immaterial. In this paper we have shown that this is due to the Dixit-Stiglitz approximation neglecting the so-called price-index effect. Once the latter is allowed for, the macroeconomic inefficiency turns out to be positively correlated with the number 
of agents. Moreover, including the price-index effect narrows the scope for New Keynesian outcomes, such as optimal nominal rigidity and multiplicity of (flexible vs inertial) equilibria.

We believe that these result, though simple, may provide some useful insights. On the one hand, from a normative perspective, one should expect the aggregate size of policy measures based on externality-internalizing mechanisms (e.g., Agell and Dillén, 1994) to be smaller, the smaller the number of agents. On the other hand, reasoning along the theoretical lines suggested in the paper may offer some perspective on the much debated problem of high unemployment in Europe. It is well known that many European countries have historically experienced a corporatist structure of economic relations, which brings about a widely spread, rent generating market power. Though at a very high level of generality, the paper may give some theoretical support to the idea that this peculiar structure of economic relations is likely to amplify the negative macroeconomic externalities of rent--seeking behaviour.

\section{Reference}

Agell J. and M. Dillén, (1994), "Macroeconomic Externalities. Are Pigouvian Taxes the Answer?", Journal of Public Economics, 53, pp. 111126.

Ball L. and D. Romer, (1989), "Are Prices Too Sticky ?", Quarterly Journal of Economics, 104, pp. 507-524.

Ball L. and D. Romer, (1990), "Real Rigidities and the Non-Neutrality of Money, Review of Economic Studies, 57, pp. 183-203.

Ball L. and D. Romer, (1991), "Sticky Prices as Coordination Failure", American Economic Review, 81, pp. 539-552.

Benassi C., A. Chirco and C. Colombo, (1994), The New Keynesian. Economics, Oxford, Basil Blackwell.

Blanchard O.J. and S. Fischer, (1989), Lectures on Macroeconomics, Cambridge Mass, MIT Press.

Blanchard O.J. and N. Kiyotaki, (1987), "Monopolistic Competition and the Effects of Aggregate Demand", American Economic Revieu, 77, pp. 647-666.

Bratsiotis G. and C. Martin, (1999), "Stabilization, Policy Targets and Unemployment in Imperfectly Competitive Economies", Scandinavian Joumal of Economics, 101, pp. 241-256.

Dixit A.K. and J.E. Stiglitz, (1977), "Monopolistic Competition and Optimum Product Diversity", American Economic Review, 67, pp. 297308. 
Dixit A.K. and J.E. Stiglitz, (1993), "Monopolistic Competition and Optimum Product Diversity : Reply", American Economic Review, 83, pp. 302-304.

Dixon H.D. and C.T. Hansen, (1999), "A Mixed Industrial Structure Magnifies the Importance of Menu Costs", European Economic Review, 43 , pp. $1475-1499$.

D'Aspremont C., R. Dos Santos Ferreira and L.A. Gérard-Varet, (1996), "On the Dixit-Stiglitz Model of Monopolistic Competition", American Economic Review, 86, pp. 623-629.

Heijdra B.J. (1998), "Fiscal Policy Multipliers : The Role of Monopolistic Competition, Scale Economies and Intertemporal Substitution in Labour Supply", International Economic Review, 39, pp. 659-696.

Heijdra B.J. and F. van der Ploeg, (1996), "Keynesian Multipliers and the Cost of Public Funds under Monopolistic: Competition", Economic Journal, 106, pp. 1284-1296.

Layard R., S. Nickell and R. Jackman, (1991), Unemployment : Macroeconomic Performance and the Labour Market, Oxford, Oxford University Press.

Yang X. and B.J. Heijdra, (1993), "Monopolistic Competition and Optimum Product Diversity : Comment", American Economic Review, 83, pp. 295-301.

Wu Y. and J. Zhang, (2000), "Endogenous Markups and the Effects of Income Taxation : Theory and Evidence from OECD Countries", Journal of Public Economics, 77, pp.383-406. 